\title{
Soil flushing of cresols contaminated soil: application of nonionic and ionic surfactants under different $\mathrm{pH}$ and concentrations
}

\author{
Saeid Gitipour*, Khadijeh Narenjkar, Emad Sanati Farvash and Hossein Asghari
}

\begin{abstract}
In this study, the viability of soil flushing on the removal of cresols (meta-, ortho-, and para-cresols) from contaminated soil has been investigated. High production and distribution of cresols in the environment indicate their potential for a widespread exposure to humans. The presence of these compounds in soil could cause a significant threat to environment, as they are toxic and refractory in nature. Cresols are persistent chemicals which are classified by the United State Environmental Protection Agency (U.S.EPA) as Group C, possible human carcinogens. Soil flushing is one of the soil remediation technologies which could by applied for treatment of hydrocarbon contaminated soil. Flushing of the contaminated soil samples was carried out by using sodium dodecyl sulfate (SDS) and Triton X-100 surfactant solutions at the concentrations of $0.1 \%, 0.2 \%, 0.3 \%$, and $0.4 \%(\mathrm{~W} / \mathrm{W})$. Three acidic, neutral, and alkaline environments were utilized by adjusting pH of the washing solutions at 3, 7 and 12 to evaluate the effect of washing environment in removing cresols. The results of this research denote that the highest removal efficiencies of $79.6 \%$ and $83.51 \%$ were achieved for $\mathrm{m}$-cresol and total o- and p-cresols, respectively, under the alkaline environment of pH12 at $0.4 \%$ (W/W) SDS concentration. Regarding performance of Triton X-100, the removal efficiencies of $80.26 \%$ and $80.14 \%$ for the above cresols were attained under similar conditions. Hence, illustrating the effectiveness of surfactants in soil flushing remediation of cresols contaminated soil.
\end{abstract}

Keywords: Contaminated soil, Cresols, SDS, Soil flushing, Surfactants, Triton X-100

\section{Background}

In recent years, contamination generated by petroleum compounds has raised concern all over the world [1]. Petroleum pollution is a global disaster that is a common phenomenon in the oil-bearing and industrial regions [2]. Because of the low solubility of hydrophobic organic compounds (HOCs) in water, the residual organic phase usually represents a long-term contamination source for soil and groundwater [3]. Cresols are isomeric substituted phenols with a methyl substituent at either ortho, meta or para position relative to the hydroxyl group [4]. These compounds are considered to be toxic and have been classified as hazardous pollutants [5]. EPA has classified cresols (m-, o-, and p-cresol) as Group C, possible human carcinogens [6-8].

In the recent decades, a broad range of physical, chemical, and biological methods have been applied for the

\footnotetext{
* Correspondence: gitipour@ut.ac.ir

Graduate Faculty of Environmant, University of Tehran, Tehran, Iran
}

remediation of soil contaminated with hydrophobic organic compounds [9]. Among all remediation technologies for treating hydrophobic organic contaminated soil, flushing is an effective and economical method, where a flushing fluid is applied to the surface of the contaminated site or injected into the saturated contaminated zone [10]. Soil flushing is the extraction of contaminants from the soil with water or other suitable aqueous solution [11]. The method usually works by applying water to the soil. Pollutants dissolved in the flushing solution are leached into the groundwater and then extracted [12,13].

Researchers have studied the usefulness of surfactants for the recovery of soils and aquifers polluted by HOCs [14-16]. As water solubility is the controlling mechanism of dissolution, additives (surfactants, cosolvents, etc.) are used to enhance efficiencies and reduce the treatment time compared to the use of water alone [17]. There are different types of surfactants, including ionic surfactant (e.g., sodium dodecyl sulfate or SDS), non-ionic surfactant (e.g., Triton X-100) and 
Table 1 Soil characteristics

\begin{tabular}{lll}
\hline Property & Test method & Value \\
\hline Water content & ASTM D 2216 & $1.83 \%$ \\
Specific gravity & ASTM D 854-92 & 2.67 \\
pH & ASTM D 4972 & 7.46 \\
Electrical conductivity & ASTM D 2974 & $213\left(\mu \mathrm{sm}^{-1}\right)$ \\
Organic content & ASTM D 2974 & $1.48 \%$ \\
USCS classification system & ASTM D 422-63 & poorly-graded sand \\
Porosity $(n)$ & - & 0.46 \\
\hline
\end{tabular}

zwitterionic surfactant (e.g., CHAPS) [18]. Anionic and nonionic surfactants have usually been chosen in surfactant remediation technology $[19,20]$.

The aim of this research was to evaluate the efficiencies of SDS, Triton X-100, and water in desorption of cresols from contaminated soil, and to assess the effects of $\mathrm{pH}$, and washing solutions concentrations on the viability of soil flushing treatment technology.

\section{Materials and methods Materials}

In this research, a poorly-graded sandy soil was used for evaluation of the efficiency of flushing experiments. Some major engineering characteristics of the soil are presented in Table 1.

Triton X-100 (TX-100) is a nonionic surfactant which has a hydrophilic head on one side and a hydrophobic tail on another side [21]. They are extensively used as preservatives or antiseptic agents in industrial and commercial products [22]. The micro heterogeneous environment of SDS contains a negatively charged surface and a hydrophobic interior [23]. For this study, SDS and Triton X-100 were purchased from Merck and Scharlau Chemie, respectively. Selected physiochemical characteristics of the surfactants used throughout this research are presented in Table 2.

Cresols, monomethyl derivatives of phenol are produced commercially by chemical synthesis or by distillation from petroleum or coal tar [24]. Physically, they are white crystalline solids or yellowish liquids with a strong phenol-like odor. The compounds are highly flammable, moderately soluble in water and soluble in ethanol, ether, acetone, or alkali hydroxides [25]. O-cresols are used as solvents, disinfectants and chemical intermediate, while pcresol is utilized in the formulation of antioxidants, fragrance and dye industries [26] and m-cresol is used to produce certain herbicides, to produce antioxidants, and to manufacture the explosive, 2,4,6-nitro-m-cresol [27]. Three isomers of cresols including meta-, ortho-, and para-cresol were purchased from Merck Chemical Company.

\section{Soil flushing remediation experiments}

The flushing apparatus used in the research consisted of a glass cylindrical column (internal diameter of $5 \mathrm{~cm}$ and the height of $35 \mathrm{~cm}$ ), primary and secondary surfactant solution reservoirs, and surfactant solution and leachate control valves. Figure 1 presents the soil flushing equipment used throughout the experiments.

\section{Methods}

Table 3 presents the permissible concentrations of different cresol isomers in residential soil regulated by various state department environmental qualities.

Based on the cleanup levels stated in Table 3, o-, m-, and p-cresols concentrations in the samples were set at 4000 ppm, 4000 ppm, and 1000 ppm, respectively. Next, samples weighing $500 \mathrm{gr}$ each, were uniformly spiked with different cresol isomers (o-cresol and m-cresol each 2gr, and p-cresol $0.5 \mathrm{gr}$ ) to bring their concentrations to $9000 \mathrm{ppm}$ in the soil. To accomplish the uniformity, cresols were diluted in dichloromethane, added to the soil, and thoroughly blended to obtain a homogenous mix. Following spiking the specimens, the glass cylindrical column was utilized and the soil was placed in it at three different layers. A rubber mallet was used for compacting each layer to a height of $5 \mathrm{~cm}$ (total of $15 \mathrm{~cm}$ of soil column). SDS and Triton X-100 surfactants at solution concentration of $0.1 \%, 0.2 \%, 0.3 \%$ and $0.4 \%(\mathrm{~W} / \mathrm{W})$ were used to flush the soil specimens. Total of 8 pore volumes of the surfactant solutions was used to flush the samples. Flushing test were carried out by using surfactant solutions at different $\mathrm{pH}$ values of 3,7 , and 12 to evaluate

Table 2 Selected physicochemical properties of surfactants in this study

\begin{tabular}{lll}
\hline Characteristic & SDS & Triton X-100 \\
\hline Molecular formula & $\mathrm{C}_{12} \mathrm{H}_{25} \mathrm{OSO}_{3} \mathrm{Na}$ & $\mathrm{C}_{14} \mathrm{H}_{22} \mathrm{O}\left(\mathrm{C}_{2} \mathrm{H}_{4} \mathrm{O}\right)_{10}$ \\
Chemical structure & 288.38 & 625 \\
Molecular weight $\left(\mathrm{g} \mathrm{mol}^{-1}\right)$ & $3.32-8.4$ & $0.2-0.31$ \\
$\mathrm{CMC}\left(\mathrm{mM} \mathrm{I}^{-1}\right)$ & $90 \sim$ & $100-98$ \\
Purity (\%) & $1.1\left(20^{\circ} \mathrm{C}\right)$ & $1.064-1.067\left(20^{\circ} \mathrm{C}\right)$ \\
specific gravity & $6.0-9.0($ Water 1\%) & $6.0-8.0($ Water 1\%) \\
pH & & $\mathrm{SO}_{3}{ }^{-\mathrm{Na}^{+}}$ \\
\hline
\end{tabular}




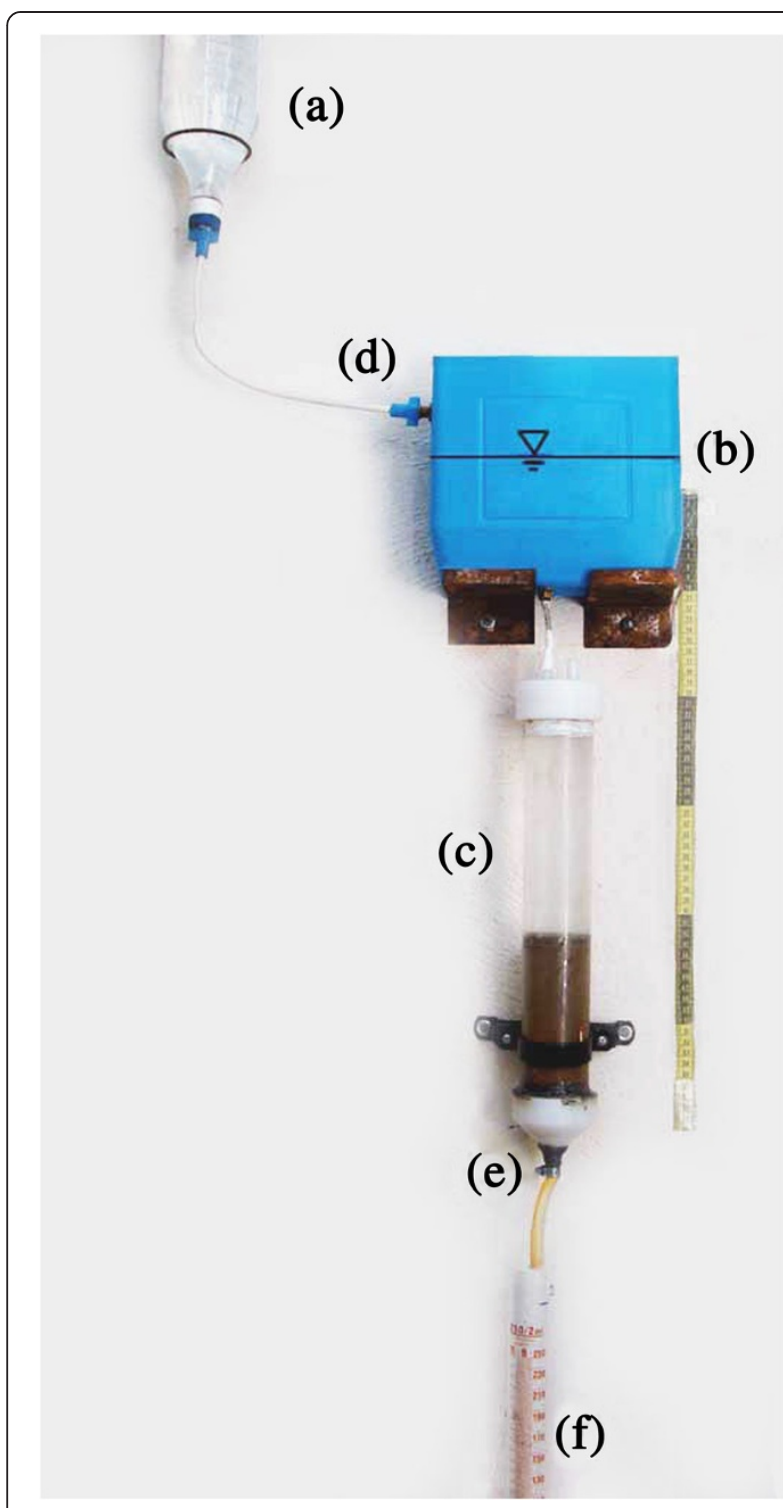

Figure 1 Soil flushing apparatus, (a) primary surfactant solution reservoirs, (b) secondary surfactant solution reservoirs, (c) glass cylindrical column (d) surfactant inflow valve, (e) leachate outflow valve, and $(f)$ graduated cylinder.

Table 3 Permissible cresols concentrations in soil based on various environmental departments

\begin{tabular}{|c|c|c|}
\hline \multicolumn{2}{|c|}{ Concentrations in residential soil $\left(\mathrm{mg} \mathrm{Kg}^{-1}\right)$} & \multirow{2}{*}{$\begin{array}{l}\text { Environmental } \\
\text { department }\end{array}$} \\
\hline para-cresol & meta- and ortha-cresol & \\
\hline 310 & 3100 & Arizona $^{a}$ \\
\hline 310 & 3100 & Wyoming $^{b}$ \\
\hline 300 & 2900 & Florida ${ }^{c}$ \\
\hline 393 & 2675 & $E P A^{d}$ \\
\hline
\end{tabular}

${ }^{\mathrm{a}}$ Arizona Department of Environmental Quality [28].

${ }^{\mathrm{b}}$ Wyoming Department of Environmental Quality [29].

CFlorida Department of Environmental Protection [30].

${ }^{\mathrm{d}}$ EPA Cleanup Criteria [31]. the effect of solution environment on removal of cresols from the samples. Following the experiments, the leachates collected from each soil flushing experiment were passed through a $0.45 \mu \mathrm{m}$ membrane filter to remove suspended solids and then was transferred into $25 \mathrm{~mL}$ screw-capped vials. The filters were then washed with a methanol solution to remove any cresol residues which possibly might have been remained on their surfaces. Next the vials were stored in a refrigerator at $4^{\circ} \mathrm{C}$ for High-performance liquid chromatography (HPLC) analysis. HPLC apparatus was used for analysis of the samples. The cresols analysis were accomplished in accordance with U.S.EPA SW-846 and Method 8270 [32].

\section{HLPC Sample analyzes}

Agilent 1100 HPLC system was used for analyses of the cresol contaminants in soil samples. The analysis was carried out by employing a modular Shimadzu LC-10 system comprised of a LC-10 AD pump, a CTO-10A column oven, a SPD-10A UV-DAD detector with wavelength of $274 \mathrm{~nm}$, a FLD detector, a CBM-10A interface, and a LC-10 Workstation. A LC-18 column $(250 \mathrm{~mm} \times$ $4 \mathrm{~mm} \mathrm{ID} \times 5 \mathrm{~mm}$ ) was employed at $26^{\circ} \mathrm{C}$ and separations were conducted in the isocratic mode, using acetonitrile: acetate buffer $(30: 70 ; \mathrm{v} / \mathrm{v})$ at a flow rate of $0.3 \mathrm{~mL} \min -1$, with an injection volume ("loop") of $20 \mathrm{~mL}$ and an accuracy of $\pm 2 \%$. The concentration of acetate buffer was $266 \mathrm{mM}$ (101 mM of acetic acid and $165 \mathrm{mM}$ of Sodium acetate trihydrate) in the HPLC analyses.

\section{Results and discussion}

\section{Removal efficiency of cresol isomers}

In this study, removal efficiencies of cresols from contaminated soil under various surfactant concentrations and $\mathrm{pH}$ values were scrutinized. Due to the overlap of o- and p-cresols' peaks during the HPLC analysis with Agilent 1100 HPLC system, these contaminants could not be differentiated from each other throughout the analysis, hence, their total concentrations have been regarded in this research. Figures 2 and 3 present the results of removal efficiency values for total o- and p-cresols, and $\mathrm{m}$-cresol under the application of SDS, Triton X-100, and water solutions.

As illustrated in Figure 2, the removal efficiencies of total o- and p-cresols flushed with water, SDS, and Triton X-100 solutions varied from $14.9 \%$ to $24 \%, 16.8 \%$ to $83.5 \%$, and $43.1 \%$ to $80.1 \%$, respectively. For $\mathrm{m}$-cresol, the removal efficiencies under the above solutions presented similar trend of removals as total o- and p-cresols (see Figure 3). The highest removal efficiency of m-cresol was $22 \%, 79.6 \%$, and $80.26 \%$ using water, SDS, and Triton X-100, respectively.

The figures also demonstrate that the removals of cresol isomers have direct relationship with surfactant type and concentration, and $\mathrm{pH}$ of flushing solution. The effects of 


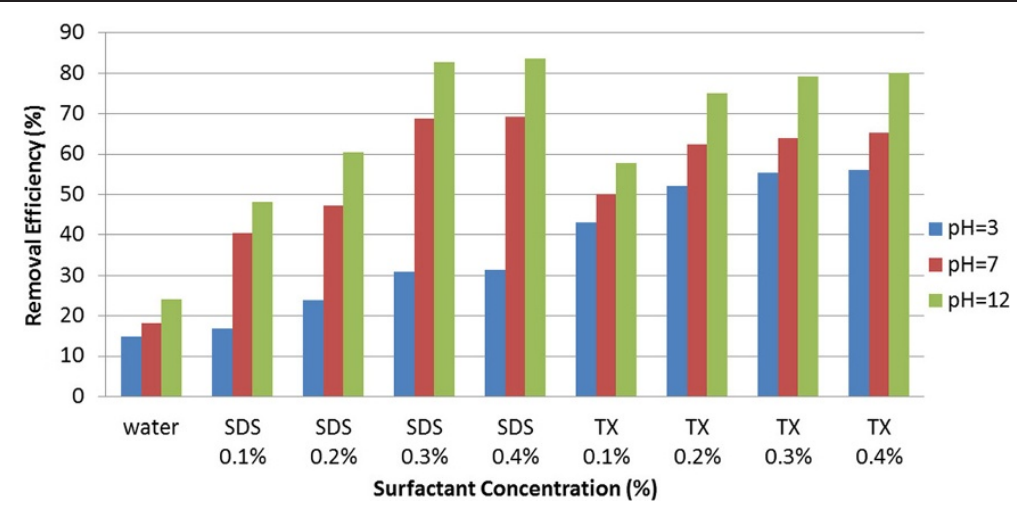

Figure 2 Total ortha- and para-cresols removal efficiencies exposed to various washing solutions under different pH conditions and concentrations.

aforementioned testing parameters on cresols removals are discussed below.

\section{Statistical analysis}

Statistically significant differences between cresol isomers removals with surfactants were evaluated by an analysis of Variance using the Minitab 16 program. The $\mathrm{p}$ values for both SDS and Triton-X 100 surfactants at different $\mathrm{pH}$ values and concentrations were obtained to be less than 0.01 showing a significant difference between the above parameters. The regression analysis conducted on the removal efficiency values of surfactants versus their concentrations and $\mathrm{pH}$ values are presented in Table 4.

Based on the regression equations presented in Table 4, the contour lines of cresols' removal efficiency values versus $\mathrm{pHs}$ and concentrations of surfactants are presented in Figure 4.

\section{Surfactant type versus cresols removal efficiencies}

The results of analysis denote that the removal efficiencies of cresol isomers (m-, o-, and p-cresols) flushed with SDS and Triton X-100 surfactants were significantly higher than that of water, indicating that water was the least effective solution in flushing of the soil. This could be attributed to surfactants amphiphilic molecules that reduce aqueous surface tension and increase the solubility of hydrophobic organic compounds [33]. Furthermore, the higher average removal efficiencies of cresols with Triton X-100 could be attributed to superior micelle formation that increased the solubility of pollutants in Triton X-100 solutions. Similar information was reported by Muherei and Junin, indicating that nonionic surfactants (i.e. Triton X-100) due to their lower CMC values perform more efficiently in removing organics than ionic surfactant (i.e. SDS) [34] (see Table 2).

\section{Effect of surfactant concentration on cresols removal efficiency}

As shown in Figures 2 and 3, the removal efficiencies of contaminants in the samples were increased with increasing of SDS and Triton X-100 concentrations up to about $3 \%$ of the surfactants. However, further increase in concentrations of surfactants to $4 \%$ did not appear to have any significant increases in removals of the cresols

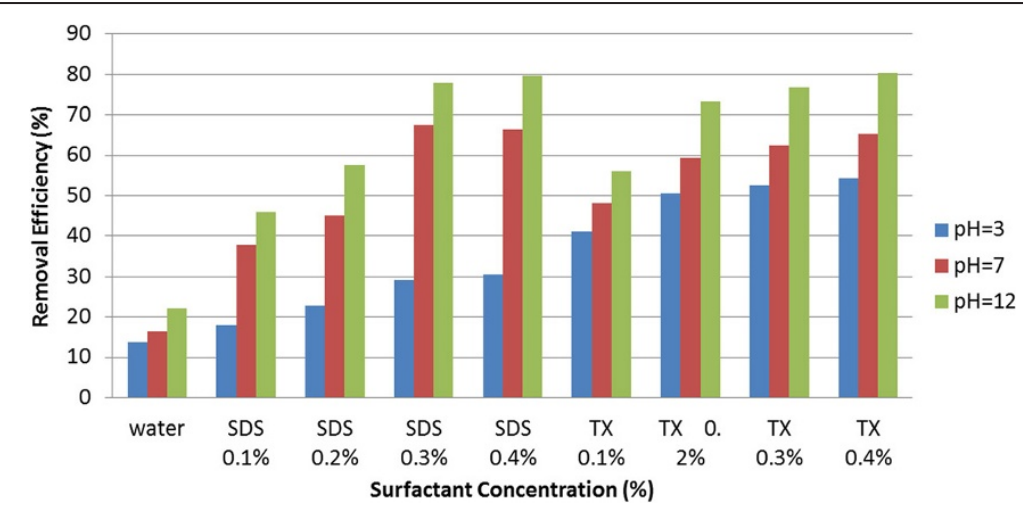

Figure 3 Meta-cresol removal efficiencies exposed to various washing solutions under different pH conditions concentrations. 
Table 4 Removal efficiencies values according to regression analysis

\begin{tabular}{lcl}
\hline Contaminant & Surfactant type & Regression equation \\
\hline $\begin{array}{c}\text { Ortha and } \\
\text { Para cresol }\end{array}$ & SDS & $\mathrm{RE}=-6.8+110.5 \mathrm{SDSC}+3.9 \mathrm{pH}$ \\
$\begin{array}{c}\text { Ortha and } \\
\text { Para cresol }\end{array}$ & Triton-X 100 & $\mathrm{RE}=15.3+112.0 \mathrm{TXC}+2.1 \mathrm{pH}$ \\
Metha cresol & $\mathrm{SDS}$ & $\mathrm{RE}=5.5+103.9 \mathrm{SDSC}+3.7 \mathrm{pH}$ \\
Metha cresol & Triton-X 100 & $\mathrm{RE}=13.8+110.7 \mathrm{TXC}+2.1 \mathrm{pH}$ \\
\hline
\end{tabular}

Abbreviation: $\mathrm{RE}=$ Removal Efficiency; SDSC $=$ SDS Concentration; $\mathrm{TXC}=$ Triton- $\mathrm{X}$ 100 Concentration.

from the soil samples. Indicating the optimum soil flushing of contaminants at about 3\% of surfactant concentrations. The figures also illustrate that, in the range of $1 \%$ to $3 \%$ concentration of surfactants, on average Triton X-100 removed the contaminants more effectively as compared with SDS.

\section{Effect of solution $\mathrm{pH}$ on cresols removal efficiencies}

The effect of the solution $\mathrm{pH}$ on removal of cresols was investigated for both of the surfactants and water. As presented in Figures 2 and 3, the removal efficiencies of cresols increased as the $\mathrm{pH}$ of surfactant solutions changed from 3 to 12. According to the analysis of soil flushing effluents, the highest removal of cresols occurred at the alkaline environment of $\mathrm{pH} 12$. Similar results for $\mathrm{pH}$ effects on cresols removals were reported by Evangelista et al. (1990) which indicated the higher cresols removals at the $\mathrm{pH} 11.5$ as compared to $\mathrm{pH} 10.5$ and $\mathrm{pH} 9.3$ washing solutions [35]. Furthermore, Salehian et al. studied the removal efficiency of diesel-contaminated soil using SDS solution as a flushing liquid. They reported that the removal efficiencies of contaminants in alkaline and neutral phases were higher than that of acidic environments [36].

\section{Conclusions}

In the present study, soil flushing tests were conducted to evaluate the effects of surfactants' concentrations and $\mathrm{pH}$ of solutions on removal of cresols from soil. The study results indicate that cresols removals had a close relationship with $\mathrm{pH}$ and concentrations of SDS and Triton X-100 surfactants. For both surfactants and water, cresols removals from soil increased with the increase of flushing solutions' $\mathrm{pH}$. Maximum removal of cresols was achieved under alkaline environment of pH12. Moreover, increase in SDS and Triton X-100 concentrations from $1 \%$ to $4 \%$ further increased the removal efficiencies of cresols in soil, with the optimum flushing at about $3 \%$ of surfactant concentrations. The above findings are in agreement with the results of a study conducted by Rosas et al., indicating that the higher extraction efficiencies of cresols was achieved by using higher concentration of nonionic Tween 80 surfactant [4]. On average, in the test conducted under different $\mathrm{pH}$ and concentration conditions, Triton X-100 presented more effective cresols' removal efficiencies than SDS surfactants. The results also indicated that the overall cresols removals in the tests increased in the order of water $<\mathrm{SDS}<$ Triton $x-100$, illustrating the effectiveness of surfactants in remediation of cresols contaminated soil.
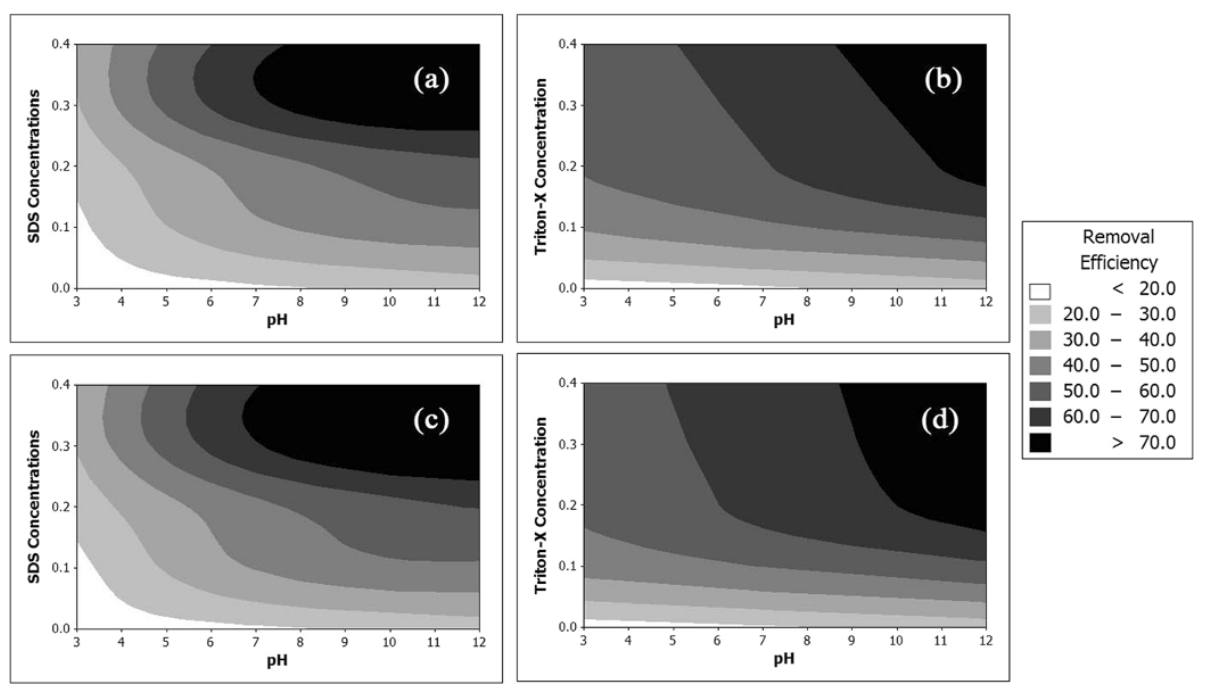

Figure 4 Contour lines of cresols' removal efficiencies versus $\mathrm{pH}$ and surfactants concentrations for (a) $\mathrm{m}$-cresol using SDS, (b) $\mathrm{m}$-cresol using Triton-x 100, (c) o and p-cresol using SDS, and (d) o and p-cresol using Triton-X 100. 


\section{Competing interests}

The authors declare that they have no competing interests.

\section{Authors' contributions}

The research is generated according to the scientific work and background of each of the authors, and all of the mentioned researchers have attempted their efforts in conducting and preparing various sections of the study (i.e., analytical methods, research concepts, experimental design, data interpretation, and conclusion). Moreover, all authors have read and approved the final manuscript.

Received: 29 July 2013 Accepted: 14 October 2014

Published online: 11 November 2014

\section{References}

1. Torabian A, Kazemian H, Seifi L, Nabi Bidhendi G, Azimi AK, Ghadiri SK: Removal of petroleum aromatic hydrocarbons by surfactantmodified natural Zeolite: the effect of surfactant. Clean - Soil Air Water 2010, 38(1):77-83.

2. Mohsenzadeh F, Chehregani Rad A, Akbari M: Evaluation of oil removal efficiency and enzymatic activity in some fungal strains for bioremediation of petroleum-polluted soils. Journal of Environmental Health Sciences \& Engineering 2012, 9:26

3. Wang $\mathrm{H}$, Chen J: Enhanced flushing of polychlorinated biphenyls contaminated sands using surfactant foam: Effect of partition coefficient and sweep efficiency. J Environ Sci 2012, 24(7):1270-1277.

4. Rosas JM, Vicente F, Santos A, Romero A: Soil remediation using soil washing followed by Fenton oxidation. Chem Eng J 2013, 220:125-132.

5. Badanthadka M, Mehendale HM: Cresols encyclopedia of toxicology. Second ed. USA: Elsevier; 2005:678-680.

6. U.S. Environmental Protection Agency: Integrated Risk Information System (IRIS) on 2-methylphenol. Washington, DC: National Center for Environmental Assessment, Office of Research and Development; 1999.

7. U.S. Environmental Protection Agency: Integrated Risk Information System (IRIS) on 3-methylphenol. Washington, DC: National Center for Environmental Assessment, Office of Research and Development; 1999.

8. U.S. Environmental Protection Agency: Integrated Risk Information System (IRIS) on 4-methylphenol. Washington, DC: National Center for Environmental Assessment, Office of Research and Development; 1999.

9. Baneshi MM, Rezaei Kalantary R, Jonidi Jafari A, Nasseri S, Jaafarzadeh N, Esrafili A: Effect of bioaugmentation to enhance phytoremediation for removal of phenanthrene and pyrene from soil with Sorghum and Onobrychis sativa. Journal of Environmental Health Sciences \& Engineering 2014, 12:24.

10. Long A, Zhang $H$, Lei $Y$ : Surfactant flushing remediation of toluene contaminated soil: Optimization with response surface methodology and surfactant recovery by selective oxidation with sulfate radicals. Sep Purif Technol 2013, 118:612-619.

11. Lee LS, Zhai X, Lee J: INDOT Guidance Document for In-Situ Soil Flushing. In West Lafayette, Indiana: Publication FHWA/IN/JTRP-2006/28-2. Joint Transportation Research Program, Indiana Department of Transportation and Purdue University; 2007. doi:10.5703/1288284314230.

12. Zhou Q, Suna F, Liua R: Joint chemical flushing of soils contaminated with petroleum hydrocarbons. Environ Int 2005, 31:835-839.

13. Navarro A, Martínez F: The use of soil-flushing to remediate metal contamination in a smelting slag dumping area: Column and pilot-scale experiments. Eng Geol 2010, 115:16-27.

14. Mata-Sandoval JC, Karns J, Torrents A: Influence of Rhamnolipids and Triton X-100 on the desorption of pesticides from soils. Environ Sci Technol 2002, 36:4669-4675.

15. Yang K, Zhu L, Xing B: Enhanced soil washing of phenanthrene by mixed solutions of TX100 and SDBS. Environ Sci Technol 2006, 40:4274-4280.

16. Zeng QR, Tang HX, Liao BH, Zhong T, Tang C: Solubilization and desorption of methyl-parathion from porous media: a comparison of HPCD and two nonionic surfactants. Water Res 2006, 40:1351-1358.

17. Atteia O, Del Campo EE, Bertin H: Soil flushing: a review of the origin of efficiency variability. Rev Environ Sci Biotechnol 2013, 12:379-389.

18. Wu F, Sun D, Wang N, Gong Y, Li L: Comparison of surfactant-assisted shotgun methods using acid-labile surfactants and sodium dodecyl sulfate for membrane proteome analysis. Anal Chim Acta 2011, 698:36-43.
19. Jafvert $\mathrm{CT}$, Van Hoof $\mathrm{PL}$, Heath J: Solubilization of non-polar compounds by non-ionic surfactant micelles. Water Res 1994, 28:1009-1017.

20. Pennell KD, Adinolfi AM, Abriola LM, Diallo MS: Solubilization of dodecane, tetrachloroethylzene in micellar solutions of ethoxylated nonionic surfactants. Environ Sci Technol 1997, 31:1382-1389.

21. Mahanthesha KR, Kumara Swamy BE, Chandra U, Sharath Shankar S, Pai KV: Electrocatalytic oxidation of dopamine at murexide and TX-100 modified carbon paste electrode: a cyclic voltammetric study. J Mol Liq 2010, 172:119-124.

22. Afkhami A, Nematollahi D, Madrakian T, Hajihadi M: Spectrophotometric determination of cationic surfactants based on their effect on the complexes of chrome Azurol S with $\mathrm{Be}^{2+}$ and $\mathrm{Al}^{3+}$ Cations. Clean - Soil, Air, Water 2010, 39(2):171-176.

23. Anitha N, Balamurugan R, Palaniandavar M: Spectral and electrochemical studies of bis(diimine)copper(II) complexes in anionic, cationic and nonionic micelles. J Colloid Interface Sci 2011, 362:243-252.

24. Sanders JM, Buchera JR, Peckhama JC, Kissling GE, Hejtmancikb MR, Chhabraa RS: Carcinogenesis studies of cresols in rats and mice. Toxicology 2009, 257:33-39.

25. World Health Organization (WHO): Cresols : health and safety guide. Geneva: World Health Organization; 1996. ISBN 10: 9241511001.

26. Chijioke UE, Fauziah SH, Agamuthu P: Characterization and toxicological evaluation of leachate from closed sanitary landfill. Waste Manage Res 2012, 30(9):888-897.

27. Agency for Toxic Substances and Disease Registry (ATSDR): Toxicological Profile for Cresols. Atlanta, GA: Public Health Service, U.S. Department of Health and Human Services; 1990.

28. Arizona Secretary of State: Title 18. Environmental Quality, Chapter 7. Department of Environmental Quality Remedial Action; 2004. Available from: http://www.azsos.gov/public_services/title_18/18-07.htm.

29. Wyoming Department of Environmental Quality: Combined Cleanup Level Tables. United States of America: 2009. Available from: http://deq.state.wy. us/volremedi/factsheets.asp.

30. Florida Department of Environmental Protection: Contaminated cleanup target levels, Chapter 62-777. Division of Waste Management; 2005. Available from: http://www.dep.state.fl.us/WASTE/quick_topics/rules/default.htm.

31. U.S. Environmental Protection Agency: Soil Clean up Criteria. 40 CFR Part 192. Washington, DC: US Environmental Protection Agency; 1998.

32. U.S. Environmental Protection Agency: Test Methods for Evaluating Solid Waste, Physical/Chemical Methods, SW-846. Method 8270: Semivolatile Organic Compounds. Washington, DC: US Environmental Protection Agency; 1986.

33. Laha S, Tansel B, Ussawarujikulchai A: Surfactant-soil interactions during surfactant-amended remediation of contaminated soils by hydrophobic organic compounds: a review. J Environ Manage 2009, 90:95-100.

34. Muherei MA, Junin R: Investigating synergism in critical micelle concentration of anionic-nonionic surfactant mixtures before and after equilibration with shale. J App/ Sci Res 2009, 5(2):181-189.

35. Evangelista RA, Allen HL, Mandel RM: Treatment of phenol and cresol contaminated soil. J Hazard Mater 1990, 25:343-360.

36. Salehian E, Khodadadi A, Hosseini B: Remediation of diesel contaminated soil using surfactants: coulumn study. American J Environ Sci 2012, 8(4):352-359.

\section{doi:10.1186/s40201-014-0129-z}

Cite this article as: Gitipour et al:: Soil flushing of cresols contaminated soil: application of nonionic and ionic surfactants under different $\mathrm{pH}$ and concentrations. Journal of Environmental Health Science \& Engineering 2014 12:129. 